\title{
“UM OLHAR SOBRE O FEMINICÍDIO"
}

\author{
"A LOOK AT THE FEMINICIDE"
}

\author{
Luiz Ricardo dos Santos ${ }^{\mathrm{I}}$
}

\begin{abstract}
RESUMO: $\mathrm{O}$ presente artigo trata-se de uma pesquisa de caráter bibliográfico em dados primários e secundários como base para o desenvolvimento do estudo, no qual foi feita análise de literatura em livros, artigos, periódicos, jornais e matérias online, com objetivo geral de apresentar as várias formas de violência contra a mulher a partir do homem como responsável pela violência, com objetivos específicos de realizar uma pesquisa sobre o histórico de violência contra a mulher, identificar os instrumentos de amparo e os direitos fundamentais inerentes às mulheres, e expor a Lei Maria da Penha quanto sua importância para a sociedade, principalmente a feminina.
\end{abstract}

Palavras-chave: Gênero. Lei Maria da Penha. Tipos de violência.

ABSTRACT: This article is a bibliographic research in primary and secondary data as a basis for the development of the study, which was made literature review in books, articles, journals, newspapers and online articles, with the general purpose of presenting the various forms of violence against women from men as responsible for violence, with specific objectives of conducting research on the history of violence against women, identifying the instruments of protection and fundamental rights inherent in women, and exposing the Maria Law da Penha as its importance to society, especially the female

Keywords: Genre. Maria da Penha Law. Types of violence.

\section{INTRODUÇÃO}

Indiscutivelmente, o feminismo foi uns dos mais importantes movimentos do século $\mathrm{XX}$, sua atuação revolucionou a sociedade e foram registrados pela batalha das mulheres em busca da universalização do direito ao voto, liberação do aborto, divisão das tarefas do lar, aprovação do divórcio, presenças nas universidades, salários iguais em relação aos dos homens, salários iguais em relação aos dos homens, e, principalmente, participação na política.

Os diretos que dependiam de ações legais, muitos foram alcançados, mais os ligados ao individualismo, ainda faltam muito porque sempre surgem novas demandas nas vidas das mulheres. A questão da violência doméstica e demais manifestações de violência teve maior destaque com a promulgação da Lei Ir.340/2006, mais conhecida como Lei Maria da Penha, uma mulher que sofreu várias agressões e tentativas de assassinato de seu ex-marido até conseguir fazer valer seus direitos. Como questão problema tem-se: Quais as consequências da tipificação

${ }^{1}$ Graduado do Curso de Administração de Empresas e administração Rural, Pós-graduado em Direito Ambiental e direito Militar, Armazenagem de grãos e Segurança alimentar, cursando Agronomia pela Universidade do Norte do Paraná - Bandeirantes-Pr. E-mail: rikardoshow@hotmail.com. 
do feminicídio proposta pelo Senado Federal, através de sua inclusão no Código Penal como forma de homicídio qualificado?

O objetivo geral é demonstrar que a elaboração da Lei 13.104/15 trata-se da efetiva prática de atos inconstitucionais decorrentes da qualificação dos crimes cometidos contra a mulher decorrente ao gênero. Como objetivos específicos: discorrer um breve histórico sobre a violência contra a mulher, abordar sobre os diferentes tipos de feminicídio existentes; identificar os atos decorrentes da aplicação das qualificadoras do feminicídio abrangem outros gêneros; verificar a (in) efetividade da lei penal como estratégia de enfrentamento da violência contra a mulher no Brasil.

O interesse pela temática tem sua origem a partir do momento em que comecei o curso. Portanto, justifica-se pela necessidade de compreender a estruturação e a dinâmica do Feminicídio no qual auxiliará nas tomadas de decisões de medidas preventivas, proativas e repressivas nas quais possam auxiliar no enfrentamento do crime, conhecendo as causas, dinâmicas regionais e os fatores que contribuem para essa violência extrema sofrida pelas mulheres.

Este trabalho uma pesquisa bibliográfica, foi "desenvolvida a partir de material já elaborado, constituído principalmente de livros e artigos científicos” (GIL, 20ı, p. 48). Além desses, somou-se a pesquisa de publicações inerentes ao assunto, de naturezas diversas, tais como artigos de jornais e revistas. Por essa razão, buscou descrever as teorias e os conceitos publicados em livros e obras congêneres, a partir dos quais foram levantados e discutidos conhecimentos disponíveis na área, identificando, analisando e avaliando sua contribuição para auxiliar e compreender: a prevenção do feminicídio, tudo para embasar os entendimentos aqui transcritos.

I Violência contra a mulher: breve histórico

A concepção de que a mulher é inferior ao homem datam desde antes de Cristo. Marcondes Filho (20II), cita que, o termo violência tem sua origem no latim violentia, que significa abuso de força, bem como o termo violare, cuja definição é o de violar o respeito devido a uma pessoa.

Segundo Cavalcanti (2018),

[...] estes termos devem ser referidos a vis, que mais profundamente, significa dizer a força em ação, o recurso de um corpo para exercer a sua força e, portanto, potência, valor, a força vital. É um ato de brutalidade, abuso, constrangimento, desrespeito, discriminação, impedimento, imposição, invasão, ofensa, proibição, sevícia, agressão física, psíquica, moral ou patrimonial contra alguém, caracteriza relações intersubjetivas e sociais definidas pela ofensa e intimidação pelo medo e temor (p. 324) 
Na Grécia Antiga, muitas diferenças eram observadas entre homens e mulheres. Estas não apresentavam direitos jurídicos bem como não recebiam educação formal, eram impedidas de comparecer em público, ficando limitadas em suas casas em um cômodo reservado (Gineceu) (PINAFI, 2017, p. 12).

E ainda pode-se dizer, conforme Cavalcanti (2018) que, Violência é, pois, o ato de brutalidade, constrangimento, abuso, proibição, desrespeito, discriminação, imposição, invasão, ofensa, agressão física, psíquica, moral ou patrimonial contra alguém, caracterizando relações que se baseiam na ofensa e na intimidação pelo medo e pelo terror (p. 122)

Teles (2018), esclarece que, quando empregamos o termo violência, referimo-nos às práticas de determinados grupos ou segmentos que forçam outros à submissão com fim de explorar, oprimir, dominar e controlar a ponto de impedir o exercício da manifestação da vontade e da autonomia por parte dos que estão ou são dominados. Tais práticas tolhem a capacidade de grupos/segmentos serem sujeitos de direitos, manifestarem e realizarem desejos, construírem perspectivas (p. 382)

A violência exercida contra a mulher apresenta raízes históricas estabelecidas pela cultura machista que julga a mulher tal qual uma propriedade do homem, ocorrendo atualmente, ainda diante de vários avanços acerca dos direitos das mulheres, gerando diversos prejuízos em suas vítimas (RITT, CAGLIARI e COSTA, 2013).

Para Porto e Bucher-Maluschke (2012):

Haveria, no caso da violência contra as mulheres, uma sociedade que estabelece/determina relações de poder assimétricas, hierarquizadas entre os sexos que, assim, determinariam as desigualdades a partir das diferenças sexuais. Existem homens que batem nas mulheres com as quais estabelecem relações afetivo-sexuais por sentirem-se com esse poder e existem as mulheres que se submetem porque esse seria seu papel nas sociedades de formação patriarcal (p. 254)

A violência contra a mulher não é característica de novos tempos, pois desde períodos mais remotos está presente na sociedade, e em vários países (SOUZA, 2018). O autor Mello (2013) comenta, que historicamente, o homem possuía o direito assegurado pela legislação de castigar a sua mulher. Observa-se que, na América colonial, mesmo após a independência americana, a legislação não só protegia o marido que "disciplinasse" a sua mulher com o uso de castigos físicos, como dava a ele, expressamente, esse direito (p. 4)

Também na Idade Média na Europa, na América do Norte e na América Latina, os maus tratos imputados às mulheres eram aceitos e até enaltecidos como práticas cujos objetivos era corrigi-las de suas manhas e erros (PINAFI, 2017). 
Ainda Giordani (2016, p. 68) expressa que no século XVIII, na França e entre outros países europeus, predominaram os reinados paterno e marital, podendo o homem julgar e punir livremente dentro de sua família, e quando as mulheres tentaram se desvincular das funções de esposa e mãe, declinando de suas obrigações domésticas: $\mathrm{O}$ comportamento do marido também se modificou, porque o casamento passou a ser entendido como "realizado por amor", interessando, portanto, aos homens que as mulheres desempenhassem papel mais importante na família. Contudo, não houve real igualdade entre homem e mulher, embora o momento aproximasse a esposa do marido (p. 7I).

No Brasil, a década de 70 foi notável pelo nascimento dos primeiros movimentos feministas organizados e politicamente comprometidos em amparo dos direitos da mulher frente o aparelho social tirano: o machismo (PINAFI, 2017).

$\mathrm{O}$ século XX foi determinante para a admissão de uma série de direitos humanos, manifestada por intrínsecas mudanças no comportamento das várias partes da sociedade em distintos locais do país e do mundo (PEREIRA e PEREIRA, 20II).

A Pós-Modernidade não suprimiu as diferenças de gênero quanto às posições de homens e mulheres na sociedade. Ainda que a mulher tenha efetivado grandes conquistas sociais, a distinção de gênero deixa-a ainda numa categoria de inferioridade em relação ao homem (SAFFIOTTI, 20II).

Souza (2018) menciona que:

Antigamente, as mulheres eram tratadas como propriedade dos homens, perdendo assim, a autonomia e a liberdade e até mesmo a disposição sobre seu próprio corpo. Há registros na história de venda e troca de mulheres, como se fossem mercadorias. Eram escravizadas e levadas à prostituição pelos seus senhores e maridos (p. 29)

Por meio da edição de inúmeras declarações e pactos, a partir de 1948, em que foi publicada a Declaração Universal de Direitos Humanos (ONU, 1948). Desde a Declaração Universal de 1948, o sistema patriarcal ocidental passou, gradativamente, nas legislações posteriores, a reconhecer a diversidade biológica, social e cultural dos seres humanos, criando declarações e pactos específicos para as mulheres. Recomendando formas de atuação dos Estados partes com a finalidade de promover a igualdade entre os gêneros, lutar contra a discriminação e a violência contra a mulher (PEREIRA e PEREIRA, 20II, p. I53).

Em 1985 foi instituído o Conselho Nacional dos Direitos da Mulher (CNDM), ligado ao Ministério da Justiça de modo a fomentar políticas que buscassem extinguir a discriminação contra a mulher e garantir sua participação nas ações políticas, econômicas e culturais do país (BRASIL, 2017, p. 34). 
Posteriormente à Década das Mulheres e até o ano de 1995, a ONU efetuou mais três conferências mundiais designadamente sobre a mulher, que foram em 1980 em Copenhagen, em I985 em Nairóbi e 1995, em Pequim (AZAMBUJA e NOGUEIRA, 2018). Em 1993, como decorrência da Conferência sobre os Direitos Humanos, foi realizada em Viena (Áustria) a Declaração de Viena para a Eliminação da Violência Contra as Mulheres, encontrando nesta, pela primeira vez, uma clara classificação das diferentes formas de violência (LOPES, 2015):

I) Violência praticada por outros membros da família (abrangendo as agressões físicas e psicológicas, as sevícias sexuais infligidas às crianças do sexo feminino, violação conjugal, mutilações genitais e outras práticas tradicionais, bem como exploração econômica); 2) Diversos tipos de violência ocorridos no contexto das comunidades locais (violação, intimidação sexual e intimidação no local de trabalho, ensino ou outras instituições, proxenetismo e prostituição forçada); 3) Violência perpetrada ou tolerada pelo próprio Estado (seja por negligência ou falta de respostas dos serviços institucionais) (p. I68)

A publicação "Violência contra a mulher - um guia de defesa, orientação e apoio" (2010) menciona que, em 1993, as Nações Unidas - ONU realizaram a Conferência Mundial sobre Direitos Humanos que reconheceu a violência contra a mulher como um obstáculo ao desenvolvimento, à paz e aos ideais de igualdade entre os seres humanos. Considerou também que a violência contra a mulher é uma violação aos direitos humanos e que esta violência se baseia, principalmente, no fato da pessoa agredida pertencer ao sexo feminino (p. 7)

Houve uma queda no número de violência contra a mulher, mas está longe de ser erradicada. Ainda assim, é relevante declarar que muitos avanços foram conquistados (LIMA, BÜCHELE e CLÍMACO, 2018, p. 6), pois "dados revelam que violência responde por aproximadamente $7 \%$ de todas as mortes de mulheres entre 15 a 44 anos no mundo todo. Especificamente no Brasil, aproximadamente 20 mil mulheres morreram entre 2003 e 2007 por causa da violência" (GOMES et al., 2012).

Em virtude dessas considerações, Borsoi, Brandão e Cavalcanti (2013) expõem a atuação do Estado:

Atualmente, o Ministério da Saúde e diversas organizações nãogovernamentais feministas têm produzido material didático, com orientações sobre o tema, e oferecido treinamentos aos profissionais de saúde de modo que eles possam identificar, apoiar e dar o devido encaminhamento às vítimas de violência. Um avanço já pode ser percebido no que tange ao enfrentamento da violência sexual pelos serviços de saúde. Tais medidas resultam tanto da compreensão de que a violência representa uma violação dos direitos humanos, como também do reconhecimento de que esta é uma importante causa do sofrimento e adoecimento, sendo fator de risco para diversos problemas de saúde (físicos e psicológicos) (p. 85) 
A promulgação da Lei "Maria da Penha" trouxe grandes benefícios às mulheres de todo o país, entretanto é alvo de grande discussão, sendo considerada inconstitucional.

I.I Tipos de violência contra a mulher

A violência contra a mulher pode se revelar-se de múltiplas maneiras e com diversos níveis de crueldade. Estas maneiras de agressão não ocorrem de forma isolada, mas sim numa subsequência evolutiva de ocorrências, na qual muitas vezes o homicídio é o ato final, como afirma Lintz (2017):

A violência, em suas mais variadas formas de manifestação, afeta a saúde, a vida: produzem enfermidades, danos psicológicos e também pode provocar a morte. Tem como objetivo causar dano a um organismo vivo, ou seja, é qualquer comportamento que tem como objetivo o de causar dano a outrem (p. 27)

É importante ressaltar o conceito de vítima, como é definido pela ONU (2016), pessoas que individual ou coletivamente, tenham sofrido danos, inclusive lesões físicas ou mentais, sofrimento emocional, perda financeira ou diminuição substancial de seus direitos fundamentais, como consequência de ações ou omissões que violem a legislação penal vigente nos Estadosmembros, incluída a que prescreve o abuso penal do poder.

Via de regra, o agressor muitas vezes possui força física e poder econômico superiores à mulher, colocando-a numa relação de domínio e pode no relacionamento, acreditando ter o direito de maltratá-la e agredi-la, tanto psicologicamente quanto fisicamente (RITT, CAGLIARI e COSTA, 2013).

A posição de violência é, antes de tudo, uma ação de violação dos direitos humanos. Pode estar integrada a dificuldades variadas, complexas e de caráter distinto. Ainda pode estar vinculado a situações conceituais indicativas à segregação entre: domínio e repressão; pretensão consciente e impulso; determinismo e livre-arbítrio (FONSECA, RIBEIRO e LEAL, 20I2).

A violência contra as mulheres se constrói, ao longo da história, com base na ideia ou na ideologia de que as diferenças biológicas são as responsáveis pelas desigualdades sociais e de injustiça. Entretanto na realidade, as diferenças biológicas existem e, ao serem respeitadas, fazem com que cada pessoa, seja individualmente original e única. Em hipótese alguma podem ser usadas para justificar as desigualdades econômicas e sociais (p. 385)

É importante citar que a violência de gênero é a agressão principal, como faz menção Carneiro e Fraga (2012), além disso, os fatores causadores da violência doméstica são compreendidos a partir da definição do fenômeno relacionado ao gênero, os quais surgem como uma estratégia de manutenção da hierarquia social, com predominância do masculino sobre o 
feminino. Com o passar das décadas, novas ferramentas surgiram para o combate à violência doméstica, inclusive a criação de uma legislação específica para o atendimento às mulheres vítimas (p. 2)

Lima, Büchele e Clímaco (2018, p. 223), identifica-se o gênero como um conjunto de características sociais, culturais, políticas, psicológicas, jurídicas e econômicas atribuídas às pessoas de forma diferenciada de acordo com o sexo. As características de gênero são construções socioculturais que variam através da história e se referem aos papéis psicológicos e culturais que a sociedade atribui a cada um do que considera "masculino" ou "feminino".

Em conformidade com Saffiotti (2011), grande parte das agressões é resultado do apoio da sociedade na edificação da desigualdade entre os gêneros. Infelizmente, a cultura machista está profundamente arraigada na sociedade, até os dias atuais.

Pode-se vislumbrar essa espécie de violência na contravenção de vias de fato, crimes de lesão corporal e contra a visa (homicídio, aborto, induzimento, instigação ou auxílio ao suicídio), inclusive na forma tentada e em qualquer conduta que ofenda a integridade anatômica e fisiológica da mulher, ou a sua saúde mental (como, por exemplo, os crimes de violência física, tais como os relacionados nos arts. 213 e 214 do CP) (p. 439)

Em outras palavras, "a violência física consiste em atos de comedimento físico sobre o corpo da mulher, ou seja, qualquer conduta que ofenda a integridade física ou a saúde corporal da mulher" (PEREIRA e PEREIRA, 20II). De acordo com entendimentos mais atualizados, o castigo frequente, não severo, igualmente é considerado violência física (SOUZA, 2018).

A definição de violência sexual é muito ampla. Envolve desde o constrangimento físico, como o uso de força ou a coação, e até mesmo a indução da sexualidade, como discorre o art. $7^{\circ}$, III da Lei Maria da Penha (BRASIL, 2016). Sendo assim, violência sexual é o termo que se emprega para situações em que a mulher é submetida à vontade sexual do homem. Esse abuso pode ocorrer por alguém da família ou de uma relação íntima.

A violência psicológica é aquela que causa um abalo emocional tão forte, que muitas vezes a mulher chega a querer pôr termo à sua própria vida. Esta forma de violência apresentase como umas das formas mais difíceis de ser diagnosticada, pois, não deixam marcas físicas, como cicatrizes ou machucados (BRASIL, 2016).

A violência patrimonial é aquela em que há a dissipação dos bens ou imóveis da mulher, provocando uma diminuição de seu patrimônio pessoal, como cita o artigo 7.ํ, IV, da Lei n.o II 340/2006 (BRASIL, 2016, p. 47). Esse tipo de violência não apresenta um tipo penal aberto ou vago, exigindo pouca interpretação do juiz para seu enquadramento penal. 
Já a violência moral é aquela conduta que configura difamação, calúnia ou injúria. Dia respeito à reputação da mulher, o que as outras pessoas pensam a seu respeito em relação aos seus atributos intelectuais, morais, físicos, entre outros (VELLOSO, 2012), tornando-se análoga à violência psicológica (DIAS, 2017).

Em conformidade com Pavanelli (2018):

[...] se a tutela for a nível penal é imprescindível que a forma da violência esteja expressamente tipificada, ou pelo Código Penal, ou por Lei Especial sob pena de não aplicação. Mas se o operador não conseguir tipificar a conduta sob a ótica penal, ainda assim poderá se valer de tutela civil sendo-lhe nomeado que proporá, no mesmo Juizado Especial, ação de natureza civil indenizatória ou de obrigação de fazer, ou não fazer para efetivar o princípio de tutela. Para tanto, basta que a conduta do agressor esteja configurada nos artigos 186 e 187 do Código Civil ou no artigo 46r do Código de Processo Civil (p. 4I).

São exemplos de violência moral quando o companheiro difama sua esposa, imputando-

lhes fatos criminosos ou até mesmo desmerecendo seus atributos físicos. Será amplamente discutida na 3. a seção a Lei $13.104 / 15$, mais conhecida como Lei do feminicídio e os tipos de feminicídio.

2. Feminicídio e os tipos

A Lei do Feminicídio não enquadra, indiscriminadamente, qualquer assassinato de mulheres como um ato de feminicídio. O desconhecimento do conteúdo da lei levou diversos setores, principalmente os mais conservadores, a questionarem a necessidade de sua implementação. Deve-se ter em mente que a lei somente aplica-se nos casos descritos a seguir:

Violência doméstica ou familiar: quando o crime resulta da violência doméstica ou é praticado junto a ela, ou seja, quando o homicida é um familiar da vítima ou já manteve algum tipo de laço afetivo com ela. Esse tipo de feminicídio é o mais comum no Brasil, ao contrário de outros países da América Latina, em que a violência contra a mulher é praticada, comumente, por desconhecidos, geralmente com a presença de violência sexual. Menosprezo ou discriminação contra a condição da mulher: quando o crime resulta da discriminação de gênero, manifestada pela misoginia e pela objetificação da mulher (SEGATO, 2015).

Segato (2015), alega que, na teoria do feminicídio, o impulso de ódio com relação à mulher se explica como consequência da infração feminina as leis do patriarcado: a norma de controle ou posse sobre o corpo feminino e a norma da superioridade masculina. A relação se ódio se inicia quando a mulher exerce autonomia no uso do seu corpo, desobedecendo às regras de fidelidade e celibato - a célebre categoria de "crimes contra a honra" masculina -, quando a mulher acende a 
posições de autoridade ou poder econômico, ou político tradicionalmente, ocupadas por homens, desafiando o delicado equilíbrio assimétrico.

Nestes casos, os estudos indicam que a resposta pode ser a agressão, e seu resultado a morte. A intenção de matar ou simplesmente ferir, ou fazer sofrer não carregar diferenças: nesta perspectiva, às vezes o feminicídios é um resultado não buscado deliberadamente pelo agressor.

Neste sentido, os crimes do patriarcado ou feminicídios são, confessadamente, crimes de poder, ou seja, crimes cuja dupla função é, simultaneamente, a retenção ou manutenção, e a reprodução do poder (2016, p. 4).

Segundo o relatório Progresso das Mulheres no Mundo 2015-2016:

Transformar as economias para realizar os direitos, a diferença salarial entre homens e mulheres, no mundo, é em média de (24\%). Somente (50\%), da população feminina com idade para trabalhar, estão ativas, enquanto entre os homens esse número chega a $77 \%$. Os cargos de cuidados com o lar e pessoas, não remunerados, são ocupados massivamente por mulheres. Ou seja, ainda que o período esteja marcado por grandes avanços para alcançar a igualdade entre os gêneros, o caminho de lutas ainda é muito grande (ONU, 2016).

Portanto, o capitalismo não mostra apenas uma faceta na história das mulheres, é dele também que vem o incentivo para que aconteça a inserção das mulheres no mercado de trabalho, pois instiga a competição de todos contra todos. Quanto a esses pequenos espaços que o capitalismo permite as mulheres conquistarem, Cunha (2014, p.), faz a seguinte crítica "os direitos conquistados pelas minorias políticas não se tornam plenos seja porque incorporados a ordem capitalista, de forma que sua eficácia só se dá na medida em que passa a atender os interesses do mercado, seja porque jamais adquirem eficácia, sendo apenas letra da lei”.

Sendo assim, para além de ser uma força de trabalho, a mulher pode reproduzir várias outras, sustentando assim o modo de produção capitalista, que se apropria e explora. Sintetizando, o patriarcado construiu um legado que ao longo da história inferiorizou, impôs dominação e subordinação sobre a mulher, agregado ao capitalismo transformou as relações patriarcais de gênero, tais quais produziram uma onda de efeitos sobre a história das mulheres com consequências algumas delas irreparáveis até a atualidade.

Contudo, a desconstrução da dicotomia público/privado que relega a mulher ao espaço do lar e dificulta sua atuação como sujeito no mundo político e do trabalho, é fator primordial para o empoderamento e autonomia do sexo feminino. Todavia, para acabar com essa separação de espaços e assim conquistar a sua autonomia, não é uma tarefa fácil e que esbarra ainda nas relações patriarcais de gênero construídas e é sobre essas relações que irá tratar no próximo tópico, para compreender porque elas são um empecilho para que o sexo feminino conquiste espaço igual ao masculino, sem submissão, opressão e/ou imposição. 
Para Souza (2018, p. II), "os direitos humanos são os direitos e liberdades básicos de todos os seres humanos e normalmente o conceito de direitos humanos tem a ideia também de pensamento e de expressão, e a igualdade perante a lei”. Eles são uma manifestação do relacionamento que deveria predominar entre os membros de uma sociedade, pessoas e Estados. Os Direitos Humanos necessitam de validação em todo Estado, seja ele grande ou pequeno, de poder aquisitivo mais alto ou baixo, independentemente da ordem social e econômica que esse país admite (PINAFI, 2017, p. 128).

Nesse contexto, a violência contra a mulher é um assunto continuamente atual e faz parte de movimentos sociais, políticos e de estudos. Anualmente, milhares de vidas, aproximadamente I 60o,ooo pessoas no mundo são mortas de forma violenta (OMS, 2016), mutiladas ou invalidadas, bem como suas famílias que ficam abaladas de maneira física ou psicológica, apresentando diversos problemas emocionais, afetivos, sexuais, mentais, econômicos e sociais (TELES, 2018, p. 381).

Os direitos humanos fundamentais têm o intuito de preservar os valores mais preciosos da pessoa humana, ou seja, a vida, a igualdade, a liberdade e a dignidade humana (BRASIL, 2016).

Dessa forma, Teles (2018) complementa:

Só quando são reconhecidos os direitos humanos, como limitador do poder do estado e como garantia de direitos individuais e coletivos, o que ocorre a partir do século XIX, é que se cria a possibilidade de pautar a violência e seu enfrentamento na agenda política (p. 383)

Pode-se dizer que, "somente quando são reconhecidos os direitos humanos das mulheres, na última década do século XX é que, de um modo geral se tomam iniciativas públicas de enfrentamento da violência de gênero" (ONU, 2016).

O Direito Internacional dos Direitos Humanos confirmou-se depois das atrocidades perpetradas ao longo da 2. ${ }^{\text {a }}$ Guerra Mundial, como parte distinta do Direito Internacional, porque os dirigentes de Estado perceberam a relevância de procurar extirpar a transgressão aos direitos dos humanos (SOUZA e FARIAS, 2016).

Ainda de acordo com Souza (2018):

Assim como no direito brasileiro existe a proteção dos direitos humanos, há também no direito Internacional esta proteção, sendo recente na história contemporânea. Surgiu no Pós-Guerra como resposta às atrocidades cometidas durante o nazismo. É naquele cenário que se desenvolve o esforço de reconstrução dos direitos humanos como paradigma e referencial ético a orientar a ordem internacional contemporânea (p. I4)

$\mathrm{O}$ art. 2. $\mathrm{o}$ estabelece que toda mulher goza dos direitos fundamentais inerentes à pessoa humana. A atual Constituição da República Federativa do Brasil conferiu dignidade e proteção 
especiais aos direitos fundamentais, sendo considerado um verdadeiro marco histórico nesta área (ANDREUCCI, 2013, p. 144).

Ainda, o autor cita que:

As normas definidoras dos direitos e garantias fundamentais têm aplicação imediata, conforme o artigo 5.ㅇ, § I., , permitindo inclusive a conclusão de que os direitos fundamentais estão protegidos não apenas diante do legislador ordinário, mas também contra o poder constituinte reformador, por integrarem o rol das denominadas cláusulas de irredutibilidade ou mínimas (ANDREUCCI, 2009, p. 157).

Já Nucci (2014, p. 23I), “o artigo 5.ํ, § 2.으, estabelece que os direitos e garantias expressos nesta Constituição não excluem outros decorrentes do regime e dos princípios por eles adotados, ou dos tratados internacionais em que a República Federativa do Brasil seja parte”.

Essa lei possibilita que outros direitos, ainda que não estejam terminantemente pronunciados na Constituição, sejam apreciados como direitos fundamentais, podendo ser concebido como o conjunto de direitos e proteção ao ser humano que tem como propósito fundamental o respeito a sua dignidade.

A 2. - Guerra Mundial foi um acontecimento determinante para os direitos fundamentais no século XX, quando foi instituída a Declaração Universal dos Direitos do Homem, frente à revolta da sociedade internacional em relação às atrocidades cometidas contra o povo judeu (SABADELL, 2015, p. 232).

Dessa forma, Lopes (2015) menciona:

Foi a primeira vez em que as Nações se uniram para discutir e elaborar uma norma de proteção dos direitos humanos, comum a todos. O Brasil é signatário desta declaração e de várias outras convenções e pactos de direitos humanos, o que constitui um grande avanço para a democracia e para a legislação Brasileira (p. 122).

A dignidade da pessoa humana está no cume da ordem jurídica brasileira, uma vez que considera o valor da pessoa humana a razão fundamental da estrutura organizacional do Estado de Direito Brasileiro.

A violência contra a mulher pode se revelar-se de múltiplas maneiras e com diversos níveis de crueldade. Estas maneiras de agressão não ocorrem de forma isolada, mas sim numa subsequência evolutiva de ocorrências, na qual muitas vezes o homicídio é o ato final, como afirma Lintz (2017): A violência, em suas mais variadas formas de manifestação, afeta a saúde, a vida: produzem enfermidades, danos psicológicos e também pode provocar a morte. Tem como objetivo causar dano a um organismo vivo, ou seja, é qualquer comportamento que tem como objetivo o de causar dano a outrem (p. 27)

É importante ressaltar o conceito de vítima, como é definido pela ONU (2016): 
Pessoas que individual ou coletivamente, tenham sofrido danos, inclusive lesões físicas ou mentais, sofrimento emocional, perda financeira ou diminuição substancial de seus direitos fundamentais, como consequência de ações ou omissões que violem a legislação penal vigente nos Estados-membros, incluída a que prescreve o abuso penal do poder.

Por norma, o agressor muitas vezes possui força física e poder econômico superiores à mulher, colocando-a numa relação de domínio e pode no relacionamento, acreditando ter o direito de maltratá-la e agredi-la, tanto psicologicamente quanto fisicamente (RITT, CAGLIARI e COSTA, 2013).

A posição de violência é, antes de tudo, uma ação de violação dos direitos humanos. Pode estar integrada a dificuldades variadas, complexas e de caráter distinto. Ainda pode estar vinculado a situações conceituais indicativas à segregação entre: domínio e repressão; pretensão consciente e impulso; determinismo e livre-arbítrio (FONSECA, RIBEIRO e LEAL, 20I2).

Conforme esclarece Cavalcanti (2008), "houve recomendação (relatório n.ำ 54/200I) para que o país realizasse profunda reforma legislativa com o fim de combater, efetivamente, a violência doméstica praticada contra a mulher", onde "a história de Maria da Penha ficou notória devido ao atraso da justiça quanto à punição do agressor" (SILVA, 2012, p. 2).

Para Gonçalves, Anjos e Pereira (2012), existem leis que vêm apenas para formalizar o que já acontece na sociedade, como a lei do divórcio, e existem as leis que tentam mudar a maneira como as pessoas vivem, como é o caso da lei que obrigou o uso do cinto de segurança. A lei que completa Maria da Penha faz parte deste segundo grupo (p. II)

Cavalcanti (2018) menciona a realidade da Lei Maria da Penha posteriormente à sua promulgação:

Após quase dois anos de vigência da Lei Maria da Penha constatamos que os índices da violência doméstica continuam altos. Observamos, porém, que houve uma diminuição considerável na reincidência, o que já é um grande avanço. Contudo, ainda precisamos lutar pela divulgação da Lei nos mais longínquos rincões brasileiros, bem como pela qualificação dos operadores do direito na questão do gênero, a fim de aplicar todos os dispositivos da Lei I1.3420/o6 em benefício das vítimas, pois verificamos que o atendimento prestado às vítimas nas delegacias de polícias não é o ideal, falta uniformidade da Lei Maria da Penha e as políticas públicas de assistência às vítimas e tratamento dos agressores ainda são insuficientes (p. 104).

Dessa forma, a principal preocupação é assegurar à mulher o direito à integridade física, moral, psíquica e sexual, e principalmente, sua dignidade. A Lei II.340/2006 tem como escopo combater os diversos fatores reprováveis que ocorrem no ambiente doméstico e familiar da mulher (BRASIL, 2016). 
2.I Lei n.o II 340/o6 - a Lei "Maria da Penha”

Maria da Penha Maia Fernandes é uma mulher que padeceu absurdas violências de seu marido em seu espaço doméstico, na década de I980, e não obteve a penalidade deste pelas leis vigentes na época, em razão à insuficiência legislativa e a demora judicial (GONÇALVES, ANJOS e PEREIRA, 2012).

A biofarmacêutica cearense Maria da Penha foi uma dentre milhares de vítimas de violência doméstica, sofrendo durante seis anos, e essa lei representa um marco muito importante na história das lutas feministas brasileiras.

Em 1983, enquanto dormia, recebeu um tiro do então marido, Marco Antônio Heredia Viveiros, que a deixou paraplégica. Com medo de sofrer mais agressões, ela dizia que fora vítima de um ladrão que disparou contra ela, resultando em uma paraplegia. Mesmo presa em uma cadeira de rodas, seu marido continuou a agredi-la (BRASIL, 2017). Depois de se recuperar, foi mantida em cárcere privado, sofreu outras agressões e nova tentativa de assassinato, também pelo marido, por eletrocussão (BRASIL, 20I6).

No ano de 1984, Maria da Penha deu início a uma exaustiva busca por justiça. Seu marido foi a júri popular sete anos depois da tentativa de homicídio, foi condenado a is anos de prisão, mas a condenação foi anulada. Posteriormente, em 1996 foi realizado um novo julgamento e seu marido foi condenado a ıo anos de prisão (BADAN, 2014).

A lei fundou-se em normas e diretrizes consagradas na Constituição Federal, no artigo 226, § 8.ํ, na Convenção da Organização das Nações Unidas sobre a eliminação de todas as formas de violência contra a mulher e na Convenção Interamericana para Punir e Erradicar a Violência contra a mulher. Registre-se o admirável fundamento político-jurídico da lei (p. 219)

A proposta foi então transformada em Projeto de Lei. Em 2005 várias audiências públicas com a participação de entidades de sociedade civil e como homenagem à Maria da Penha, foi sancionada a Lei n. II 340/2006 pelo presidente Luiz Inácio Lula da Silva, que coíbe a violência doméstica contra mulheres (AME).

A Lei Maria da Penha revoluciona o ordenamento jurídico ao determinar de forma expressa a proteção da mulher no âmbito domiciliar, traduzindo a tutela do Estado sobre a violência que permanece oculta da sociedade e sobre o indivíduo, muitas vezes, mais fraco nas relações afetivas. A norma abrange não só a violência física, mas a moral e psicológica, prevendo ainda, o imediato afastamento do agressor do seio domiciliar (p. I).

Para Gonçalves, Anjos e Pereira (2012), existem leis que vêm apenas para formalizar o que já acontece na sociedade, como a lei do divórcio, e existem as leis que tentam mudar a 
maneira como as pessoas vivem, como é o caso da lei que obrigou o uso do cinto de segurança. A lei que completa Maria da Penha faz parte deste segundo grupo (p. II)

Nesse contexto, Cavalcanti (2018) menciona a realidade da Lei Maria da Penha posteriormente à sua promulgação:

\begin{abstract}
Após quase dois anos de vigência da Lei Maria da Penha constatamos que os índices da violência doméstica continuam altos. Observamos, porém, que houve uma diminuição considerável na reincidência, o que já é um grande avanço. Contudo, ainda precisamos lutar pela divulgação da Lei nos mais longínquos rincões brasileiros, bem como pela qualificação dos operadores do direito na questão do gênero, a fim de aplicar todos os dispositivos da Lei I1.3420/o6 em benefício das vítimas, pois verificamos que o atendimento prestado às vítimas nas delegacias de polícias não é o ideal, falta uniformidade da Lei Maria da Penha e as políticas públicas de assistência às vítimas e tratamento dos agressores ainda são insuficientes (p. 104)
\end{abstract}

Dessa forma, a principal preocupação é assegurar à mulher o direito à integridade física, moral, psíquica e sexual, e principalmente, sua dignidade. A Lei II.340/2006 tem como escopo combater os diversos fatores reprováveis que ocorrem no ambiente doméstico e familiar da mulher (BRASIL, 2018).

O interesse da Lei é com a proteção contra a violência praticada pelos homens ou mulheres (sujeitos ativos da violência) com os quais a mulher (sujeito passivo da violência) teve uma relação familiar ou afetiva, ou até mesmo por qualquer pessoa que conviva no âmbito familiar ou doméstico. É necessário discriminar a diferença entre sujeitos ativo e passivo, como o faz Silva (2012) ao afirmar: "diante disso, é certo que sujeito ativo é aquele que pratica a conduta descrita no tipo penal; já o sujeito passivo é a vítima, ou seja, o titular do bem jurídico tutelado”. Assim, Dias (2017) menciona:

[...] por mais que se tente minimizar sua eficácia e questionar sua valia, Maria da Penha veio pra ficar. As manifestações têm uma justificativa: o absoluto descaso de que sempre foi alvo a violência doméstica [...] a partir do momento em que a lesão corporal leve foi considerada de pequeno potencial ofensivo com a possibilidade de os conflitos serem solucionados de forma processual, acabou banalizada a violência intrafamiliar (p. 299)

Em relação à inconstitucionalidade da Lei Maria da Penha, Stela Cavalcanti (2018) lembra que não há dúvidas de que o texto aprovado constitui um avanço para a sociedade brasileira, representando um marco indelével na história da proteção legal conferida às mulheres. Entretanto, não deixa de conter alguns aspectos que podem gerar dúvidas na aplicação, e até mesmo, opções que revelam uma formulação legal afastada da melhor técnica e das mais recentes orientações criminológicas e de política criminal, daí a necessidade de analisá-la na melhor perspectiva para as vítimas, bem como discutir a melhor maneira de implementar todos os seus preceitos (p. 324)

Ainda sobre o tema, Campos (2013) cita: 
Ao estabelecer uma nova política criminal no país, a Lei Maria da Penha rompeu com o tradicional pensamento criminológico e gerou fortes reações sobre sua inconstitucionalidade [...] os argumentos contrários vão desde críticas ao feminismo como corresponsável pelo expansionismo penal aos seus aspectos penais inovadores. Assim, argumentos de inconstitucionalidade por violar o princípio da igualdade entre homens e mulheres, aumento desproporcional da pena e não aplicação da Lei 9.099/95 têm sido recorrentes entre setores relutantes a aplicação da Lei Maria da Penha (p. 246)

Muitos autores fazem referência favorável a Lei Maria da Penha, não compreendendo que exista inconstitucionalidade da lei "maria da penha".

A Constituição Federal, em seu art. 226, § 8º "impõe ao Estado assegurar a assistência à família na pessoa de cada um dos que a integram, definindo meios para impedir a violência no âmbito de suas relações" (CARDOSO, 20II). Dessa forma, o bem jurídico tutelado pela Lei no II.340/2006 é a integridade física, moral e econômica da mulher, abrangendo desde a proteção mais grave, correspondente à morte, estendendo-se à lesão corporal e culminando com toda espécie de sofrimento (GIORDANI, 2016).

A Lei no II.340/o6, mesmo não sendo completa, assim como outras leis existentes, demonstram uma estrutura apropriada e exclusiva para acolher a complexidade e o processo da manifestação da violência doméstica ao prever dispositivos de prevenção, amparo às vítimas, políticas públicas e penalidade menos flexíveis para os agressores (DIAS, 2017).

A lei Maria da Penha trouxe grandes mudanças e benefícios, tais como as medidas integradas de proteção, as medidas protetivas de urgência, a atuação do Ministério Público, a agilização nos processos e a competência delegada à autoridade policial, como afirma Kato (2018), outra importante mudança é a alteração de competência mediante qual o juiz da Vara de Violência Doméstica e Familiar contra a Mulher terá competência, em caso de violência, para apreciar e julgar não só o crime supostamente praticado, mas os casos que envolverem questões de família, pensão, separação e guarda dos filhos etc. (p. 28o)

Em relação à atuação do Ministério Público, Cardoso (20II) alude que:

Define inclusive que cabe ao Poder Público desenvolver políticas que visem garantir os direitos humanos da mulher no âmbito das relações domésticas e familiares, protegendo de toda forma de negligência, discriminação, exploração, violência, crueldade e opressão. Também lhe compete criar condições necessárias para o efetivo direito à vida, à segurança, à saúde, à moradia, ao acesso à justiça, ao esporte, ao lazer, ao trabalho, à dignidade, ao respeito e à convivência familiar e comunitária (p. 2)

Tais alterações tornaram os processos mais céleres, como menciona Pasinato (2018):

A Lei Ir.340/2006 trouxe várias alterações para o enfrentamento da violência contra as mulheres no plano jurídico. $\mathrm{Na}$ esfera da intervenção policial foram retomados os procedimentos de registro do boletim de ocorrência e instauração de inquérito policial, que prevê o prazo de 30 dias para que eventuais 
testemunhas sejam localizadas e ouvidas, bem como sejam colhidas as versões da vítima e de seu agressor (p. 343)

Com a Lei, fica estabelecido que a polícia possua o direito de investigação e poderia tomar as medidas oportunas prontamente: "na hipótese da eminência ou da prática de violência doméstica e familiar contra a mulher, a autoridade policial que tomar conhecimento da ocorrência adotará, de imediato, as providências legais cabíveis” (BRASIL, 2016).

Consta na Lei Maria da Penha (BRASIL, 2016) as medidas, no Art. 22. Constatada a prática de violência doméstica e familiar contra a mulher, nos termos desta Lei, o juiz poderá aplicar, de imediato, ao agressor, em conjunto ou separadamente, as seguintes medidas protetivas de urgência, entre outras:

II - afastamento do lar, domicílio ou local de convivência com a ofendida;

III - proibição de determinadas condutas, entre as quais:

a) aproximação da ofendida, de seus familiares e das testemunhas, fixando o limite mínimo de distância entre estes e o agressor;

b) contato com a ofendida, seus familiares e testemunhas por qualquer meio de comunicação;

c) frequentação de determinados lugares a fim de preservar a integridade física e psicológica da ofendida;

As medidas cautelares de natureza penais, previstas no artigo 22, I, II e III da Lei Maria da Penha, têm por desígnio prevenir e assegurar, particularmente, a integridade física, psicológica e patrimonial da vítima e de seus familiares, para que a mulher possa atuar de maneira livre, sem violência, e ter resguardado sua saúde física e mental, bem como gerar as bases essenciais para o definitivo exercício dos direitos proferidos no artigo 3.ํ, caput. da Lei II.340/2006 (BRASIL, 2016).

Ainda Cardoso (20II) menciona que o agressor pode ser enquadrado cível e criminalmente:

Ao tratar do procedimento, a Lei Ir.340/o6 faculta à União (no Distrito Federal e Territórios) e aos Estados a criação dos Juizados de Violência Doméstica e Familiar contra a Mulher, que são órgãos da Justiça Ordinária com competência cível e criminal responsável pelo processo, julgamento e execução das causas decorrentes da prática da violência contra a mulher. Ainda, a própria norma, em seu art. 4I, prevê que independentemente da pena prevista, não se aplica a Lei 9.099/95 aos crimes previstos em seus dispositivos (p. 2)

O descumprimento dessas medidas pode ocasionar um risco real para a vítima, motivo pelo qual a lei permite, no artigo so e seu parágrafo único, que a autoridade policial que tiver apurando os fatos, tome as providências cabíveis e necessárias para afastar o risco decorrente do descumprimento da medida de proteção determinada, como supracitado.

Um tipo de medida protetiva é o afastamento do agressor do lar, como cita Cardoso (2OII): 
Não se trata de preocupação inédita, pois precedida de outros ordenamentos que tentavam trilhar algum tipo de proteção à mulher, tais como a Lei I0.455/o2 que acrescentou o parágrafo único do art. 69, da Lei 9.099/95, e consiste em uma medida cautelar que afasta o agressor do lar em caso de violência doméstica; ou até mesmo a criação de um subtipo de lesão corporal leve, decorrente da violência doméstica, acrescido ao art. 129 pela Lei ro.886/o4, aumentando a pena mínima de 3 para 6 meses (p. 8)

Ainda sobre o tema, Pinafi (2017) discorre que as medidas cautelares de afastamento possuem o intuito de:

A medida cautelar de afastamento do agressor do lar, domicílio ou local de convivência com a ofendida, visa impedir ou dificultar que as agressões sejam perpetradas ou reiteradas no lar conjugal, bem como afastar as pressões e ameaças contra a vítima e seus dependentes ou familiares (p. 178)

Nesse prisma, a Lei Maria da Penha deixou claro que historicamente sempre ocorreu a desigualdade e discriminação da mulher frente ao homem. Nessa vertente, o único modo de afastar o agressor da residência conjugal era por meio de uma ação cautelar de separação de corpos. Ainda assim, por ser o registro policial um documento produzido unilateralmente, era difícil conseguir sua aceitação como prova para concessão da liminar (BARSTED, 2016). Dessa forma, o agressor não será mais enquadrado em outras leis, onde a medida punitiva é o pagamento de cestas básicas.

Para Teles (2018), a Lei Maria da Penha convoca o Estado e a sociedade a terem uma nova postura para com as vítimas da violência doméstica e familiar e para isso determina que o judiciário possa conceder medidas protetivas que vão assegurar as mulheres condições de igualdade para romper com as situações de conflito e tensão, sem deixar de ter atendidas suas necessidades básicas e seus interesses (p. 389)

A Lei da Violência Doméstica e Familiar contra a Mulher (BRASIL, 2016) apresenta em seu art. 8. que "a política pública que visa coibir a violência doméstica e familiar contra a mulher deve ser feita por meio de um conjunto articulado de ações da União, dos Estados, do Distrito Federal e dos Municípios".

\section{Conclusão}

A violência doméstica contra a mulher não, é algo recente, vem ultrapassando várias décadas, sob relações de poder do homem sobre a mulher. É um fenômeno cultural que nos tempos atuais ainda viola alguns direitos considerados inalienáveis ao ser humano, como o respeito à dignidade e à vida. A violência não escolhe classe social e raça, pois está presente em todas elas.

Entretanto, as classes menos favorecidas possuem uma tendência ao fato, tendo em vista a realidade de subalternidade vivenciada e as expressões da questão social. Depois de anos de 
obscuridade, diante da falta de lei que respaldasse o combate à violência doméstica, a Lei Maria da Penha foi um avanço em seu enfrentamento, por legitimaras medidas protetivas de urgência, que visam resguardar a integridade física e psíquica das mulheres em situação de violência doméstica.

Todavia cabem algumas observações que incorrem na fragilidade da aplicação, como a inclusão da mulher em risco iminente, em programas assistenciais nas três esferas do governo, a garantia da punição do agressor, principalmente na extinção das penas pecuniárias como o pagamento de fiança e cestas básicas. São gargalos que desestruturam a rede de atendimento, porque sem a efetivação do que está posto na lei, os demais encaminhamentos ficam comprometidos.

A expressão de violência cometida contra a mulher ainda não tem um número definido, visto que muitas mulheres ainda camuflam os fatos ocorridos, seja por medo do agressor, por vergonha da sociedade e até mesmo para não expor a família. Se todos os casos fossem denunciados, seria mais fácil registrar a real magnitude que as lesões corporais, psicológicas e outras ocasionam em todo o Brasil. Sem a denúncia os agressores reafirmam a impunidade, se aproveitam da fragilidade e silêncio da vítima.

A implementação da Lei Maria da Penha representa um estímulo e dá um caráter de urgência para a realização de novos estudos e pesquisas voltados a este novo olhar sobre o lugar dos homens no debate e nas ações sobre a violência contra a mulher. É necessário, no entanto, que o discurso feminista não seja deslocado, pois, foi a partir de seus esforços que a violência contra a mulher foi percebida como um grave problema de saúde pública e violação dos direitos humanos.

Acredita-se que esta pesquisa contribua socialmente como forma de informação sobre a questão abordada, que esses estudos compartilhem também as referências teóricas adotadas para compreender e definir o fenômeno social da violência contra as mulheres e a posição das mulheres em relação à violência.

\section{REFERÊNCIAS}

ALGERI S. SOUZA. L. M. Violência contra crianças e adolescentes: um desafio no cotidiano da equipe de enfermagem. Revista Latino- Americana de Enfermagem. V.I4, $\mathrm{n}^{\mathrm{o}} 4, \mathrm{p} .625$ a 631.2016 .

ANDREUCCI, Ricardo Antonio. Legislação Penal Especial. São Paulo: Saraiva, 2013. 


\section{ASSOCIAÇÃO DE MULHERES EMPREENDEDORAS - AME. Projeto Maria da Penha. A} história de Maria da Penha. Disponível em: <http://www.mariadapenha.org.br/a-lei/a-historiada-maria-da-penha/>. Acesso em: o9 out. 2016.

AZAMBUJA, Mariana Porto Ruwer de; NOGUEIRA, Conceição. Introdução à violência contra as mulheres como um problema de direitos humanos e de saúde pública. Saúde Soc., São Paulo, v. $17, \quad$ n. $3, \quad$ set. 2018. Disponível em: 〈http://www.scielo.br/scielo.php?script=sci_arttext\&pid=Soro4129020080003000II\&lng $>$. Acesso em: o9 out. 2019.

BADAN, Mima (Wilma). Lei "Maria da Penha". Powerpoint. Disponível em: $\langle$ http://pt.scribd.com/doc/3391827/Lei-Maria-da-Penha〉.2014.

BARSTED, Leila Linhares. $O$ avanço legislativo no enfrentamento da violência contra as mulheres. Brasília: Agende, 2016.

BORSOI, Tatiana dos Santos; BRANDÃO, Elaine Reis; CAVALCANTI, Maria de Lourdes Tavares. Ações para o enfrentamento da violência contra a mulher em duas unidades de atenção primária à saúde no município do Rio de Janeiro. Interface (Botucatu), Botucatu, v. 13, n. 28, Mar. 2013.

Disponível: http://www.scielo.br/scielo.php?script=sci_arttpid=SI4I4328320114\&lng=en\&nrm=iso $>$. Acesso em 09 out. 2019.

BUCHER-MALUSCHKE, J. S. N. F. Família, lócus de vivências: Do amor à violência. In T. Féres-Carneiro (Org.), Família e casal: Arranjos e demandas contemporâneas (pp.169-199). São Paulo: Loyola. 2012

.Relações conjugais em transformações e sofrimento psíquico: Uma sociedade em transição. In I. Costa, A. F. Holanda, F. Martins, \& M. I. Tafuri (Orgs.), Ética, linguagem e sofrimento (pp. 295-305). Brasília: Positiva. 2012.

BRASIL. Lei n. II.340 (Lei Maria da Penha). Cria mecanismos para coibir a violência doméstica e familiar contra a mulher, nos termos do § 8 o do art. 226 da Constituição Federal. Diário Oficial 
da União, 2016; 8 ago. Disponível em:< http://www.planalto.gov.br/CCIVIL/_Ato20042010/2010/Lei/Li1340.htm>.

Secretaria Especial de Políticas para as Mulheres (SPM). Pacto Nacional pelo Enfrentamento da Violência contra a Mulher. Brasília: SPM, 2016. Disponível em: $\langle$ http://200.130.7.5/spmu/docs/pacto_violencia.pdf $\rangle$.

Secretaria Especial de Políticas para as Mulheres (SPM). II Plano Nacional de Políticas para as Mulheres. Brasília: SPM, 2017. Disponível em:< http://200.130.7.5/spmu/docs/Livreto_Mulher.pdf>. Acesso em: o9 out. 2019.

CARDOSO, Camila Daros. Competência para as medidas cautelares cíveis na Lei Maria da Penha. Jus Navigandi, Teresina, ano 16, n. 2793, 23 fev. 201r. Disponível em: 〈http://jus.uol.com.br/revista/texto/18556〉.

CAMPOS, Carmen Hein de. Lei Maria da Penha: mínima intervenção punitiva, máxima intervenção social. Revista Brasileira de Ciências Criminais. Editora Revista dos Tribunais, ano 16, n. 73 , julho- ago 2013, p. 244 a 267.

CARNEIRO, Alessandra Acosta; FRAGA, Cristina Kologeski. A Lei Maria da Penha e a proteção legal à mulher vítima em São Borja no Rio Grande do Sul: da violência denunciada à violência silenciada. Serviço Soc. Saúde, São Paulo, n. ııo, Junho 2012. Disponível em: $<$ http://www.scielo.br/scielo.php?script=sci_arttext\&pid=So101662820120002000o8\&lng=en\&nr $\mathrm{m}=$ iso $>$. Acesso em: 07 out. 2019.

CAVALCANTI, Stela Valéria Soares de Farias. Violência doméstica contra a mulher no Brasil. 2. ed. Salvador: Podivm, 2018.

CUNHA, Bárbara Madruga da. Violência contra a mulher, direito e patriarcado: perspectivas de combate à violência de gênero. 20I4. Disponível em: < http://www.direito. II6 Id on Line Rev. Mult. Psic. V.13, N. 44, p. 97-II7, 2019 - ISSN I98I-II79 Edição eletrônica em http://idonline.emnuvens.com.br/id ufpr.br/portal/wp-content/uploads/2014/12/ArtigoB\% 3 \% $\%$ Arbara-Cunha-classificado-em7\% 2 2\%BA-lugar.pdf>. Acesso em: 25 de Setembro de 2019. 
DIAS, Maria Berenice. A lei Maria da Penha na justiça: a efetividade da Lei II.340/2006 de combate à violência doméstica e familiar contra a mulher. São Paulo: Revista dos Tribunais, 2017.

DINIZ, G. R. S. e Angelim, F. P. (2017). Violência doméstica - porque é tão difícil lidar com ela?. Revista de Psicologia da Unesp, 2(I), 20-35.

FONSECA, Denire Holanda da; RIBEIRO, Cristiane Galvão; LEAL, Noêmia Soares Barbosa. Violência doméstica contra a Mulher:. Realidades e Representações Sociais. Psicol. Soc. Belo Horizonte, v 24, n. 2, agosto 2012. Disponível em: $\langle$ http://www.scielo.br/scielo.php?script=sci_arttext\&pid=So1021822012000200008\&lng=en\&nr $\mathrm{m}=$ iso $>$.

GIORDANI, Annecy Tojeiro. Violência contra a mulher. São Caetano do Sul: Yendis, 2016.

GOMES, Nadirlene Pereira et al. Homens e mulheres em vivência de violência conjugal: características socioeconômicas. Revista Gaúcha de Enfermagem, Porto Alegre, v. 33, n. 2, June 2012

em: $<$ http://www.scielo.br/scielo.php?script=sci_arttext\&pid=S198314472012000200016\&lng=en\&nr $\mathrm{m}=$ iso $>$. Acesso em: 08 set. 2019 .

GONÇALVES, Fabiana Santos; ANJOS, Jocimar Augusto dos; PEREIRA, José Ricardo Moura. Lei Maria da Penha: contexto histórico e casos concretos de Aplicabilidade. Revista Facnopar, 2012. Disponível em: 〈http://facnopar.com.br/revista/2012/lei_maria_da_penha.pdf〉.

KATO, Shelma Lombardi de. Lei Maria da Penha: uma lei constitucional para enfrentar a violência doméstica e construir a difícil igualdade de gênero. Revista Brasileira de Ciências Criminais. Editora Revista dos Tribunais, ano I6, n. 71, março- abril 2018, p. 266 a 296.

LIMA, Daniel Costa; Buchele, Fátima; Clímaco, Danilo de Assis. Homens, Gênero e Violência contra a Mulher. Saúde e Sociedade, São Paulo, v 17, n. 2, junho de 2018. Disponível em: $<$ http://www.scielo.br/scielo.php?script=sci_arttext\&pid=Soro42902008000200008\&lng=en\&nr $\mathrm{m}=\mathrm{iso}>$. Acesso em: o9 out. 2019.

LINTZ, Sebastião. O crime, a violência e a pena. Campinas - SP. 2017. 
LOPES, C. B. Direitos humanos das mulheres: dois passos à frente, um passo atrás. In: RODRIGUES, A. M. et al. 2005 (Org.). Direitos humanos das mulheres. Coimbra: Coimbra Ed., 2015. p. 157-170.

NUCCI, Guilherme de Souza. Leis penais e processuais comentadas. 3. Ed. São Paulo: Editora Revista dos Tribunais, 2014.

MARCONDES FILHO, C. Violência fundadora e violência reativa na cultura brasileira. São Paulo em Perspectiva. São Paulo, v.15 n.2, abr/jun de 20II. Disponível em: $<$ http://www.scielo.br/scielo.php?script=sci_arttext\&pid=So1028392001000200004\&lng=en\&nr $\mathrm{m}=$ iso $>$. Acesso em: o7 out. 2019.

ONU - ORGANIZAÇÃO DAS NAÇÕES UNIDAS. Estudo das formas de violência contra a mulher. Nova York, 2016. Disponível em: 〈http://daccess-ods.un.org/TPM/8874883.html〉

PASINATO, Wânia. Violência contra as mulheres e legislação especial, ter ou não ter? Eis uma questão. Revista Brasileira de Ciências Criminais. Editora Revista dos Tribunais, ano I6, n. 70, jan-fev 2018, p. 321 a 360.

PEREIRA, Malila Natascha da Costa; PEREIRA, Maria Zuleide da Costa . A violência doméstica contra a mulher. ESPAÇO DO CURRÍCULO, v.4, n.I, pp.22-34, Março a Setembro de 20II.

PINAFI, Tânia. Violência contra a mulher: políticas públicas e medidas protetivas na contemporaneidade. Governo do Estado de São Paulo. Abril/maio de 2017. Disponível em: $\langle$ http://www.historica.arquivoestado.sp.gov.br/materias/anteriores/edicao2I/\#topo〉.

RITT, Caroline Fockink; CAGLIARI, Cláudia Taís Siqueira; COSTA, Marli Marlene da. Violência cometida contra a mulher compreendida como violência de gênero. Universidade de Santa Cruz do Sul - RS, UNISC. 2013, 20 p. Disponível em: 〈http://www.ufrgs.br/nucleomulher/arquivos/artigo_violencide\%2ogenero〉.

SABADELL, Ana Lucia. Manual de Sociologia Jurídica: introdução a uma leitura externa do Direito. 3 ed. São Paulo: Revista dos Tribunais, 2015. 
SAFFIOTI, Heleieth. Gênero, patriarcado e violência. São Paulo: Perseu Abramo, 201 .

SEGATO, Rita Laura. Qué es un feminicidio?, disponível em http://192.64.74.193/ genera/newsite/images/cdrdocuments/publicaciones/que_es_un_feminic idio.pdf.2015.

SILVA, Dayane de Oliveira Ramos. Aplicabilidade da Lei Maria da Penha: Um olhar na vertente do gênero feminino. Âmbito Júridico, Nassau-Recife PE, 2012, Disponível em: 〈http://www.ambitojuridico.com.br/site/index.php?n_link=revista_artigos_leitura\&artigo_id= 8892>.

SOUZA, Mércia Cardoso de; FARIAS, Déborah Barros Leal. Os Direitos Humanos das Mulheres sob o olhar das Nações Unidas. Universidade de Fortaleza (UNIFOR), 2016, i2 p. Disponível:_http://www.fa7.edu.br/recursos/imagens/File/direito/ic/iv_encontro/direitoshu manosdasmulheres.pdf $>$.

SOUZA, Sérgio Ricardo de. Comentário a Lei de Combate à Violência Contra a Mulher. 2 ed. Curitiba: Juruá, 2018.

TELlES, Maria Amélia de Almeida. O protagonismo das vítimas de violência doméstica e familiar. Revista Brasileira de Ciências Criminais. Editora Revista dos Tribunais, ano 18, n. 86, set- out 2018, p. 38r a 392. 